\title{
EFEITOS DO CYCOCEL NA FERTILIDADE DE GEMAS E NO CRESCIMENTO DOS RAMOS DE VIDEIRAS cv ITÁLIA (Vitis vinifera L.) ${ }^{1}$
}

\author{
RENATO VASCONCELOS BOTELHO ${ }^{2,3}$, ERASMO JOSÉ PAIOLI PIRES $^{4}$, MAURILO MONTEIRO TERRA $^{4}$
}

\begin{abstract}
RESUMO - A baixa fertilidade de gemas tem sido um dos fatores limitantes da produção em vinhedos do Estado de São Paulo, estando este problema relacionado, em muitos casos, ao excesso de vigor das plantas. Neste contexto, um experimento foi conduzido em vinhedo comercial da cultivar de uva de mesa Itália, localizado no município de São Miguel Arcanjo (SP). O delineamento experimental foi em blocos casualizados, com 6 tratamentos e 4 repetições. Os ramos foram pulverizados com soluções de cycocel, nas doses de $0 ; 500 ; 1.000 ; 1.500 ; 2.000$ e 2.500 mg.L. $\mathrm{L}^{-1}, 60$ dias após a poda. As variáveis avaliadas foram: porcentagem de gemas férteis, distribuição das gemas férteis por setor do ramo, porcentagem de gemas mortas, peso, comprimento e diâmetro de entrenós. Aplicações de cycocel aumentaram linearmente a porcentagem de gemas férteis e a proporção de gemas férteis entre a $1^{\mathrm{a}}$ e a $5^{\mathrm{a}}$ gema basal. Além disso, este retardador de crescimento reduziu a porcentagem de gemas mortas e o peso dos entrenós, apresentando efeito quadrático para estas variáveis.
\end{abstract}

Termos para indexação: uva, regulador vegetal, fisiologia do florescimento.

\section{EFFECTS OF CYCOCEL ON BUD FERTILITY AND SHOOT GROWTH OF ITALIA GRAPEVINES (Vitis vinifera L.)}

ABSTRACT - The low bud fertility has been one of the most limiting factors in vineyards at São Paulo State, and this problem has been correlated, in many cases, to the excess of plant vigor. In this context, a trial was carried out in a commercial vineyard of 'Italia' table grape, located at São Miguel Arcanjo (SP), Brazil. The experimental design was in complete randomized blocks with six treatments and four replications. The vine shoots were sprayed with cycocel at $0,500,1000,1500,2000$ and 2500mg.L $\mathrm{L}^{-1}, 60$ days after pruning. The variables evaluated were: percentage of fertile buds; distribution of fertile buds per shoot sector; percentage of bud necrosis; weight, length and diameter of internodes. Applications of cycocel linearly increased the percentage of bud fertility and the proportion of fertile buds between first and fifth basal buds. Furthermore, this growth regulator reduced the incidence of bud necrosis and the weight of internodes, presenting quadratic effect for these variables.

Index terms: grapes, plant regulator, flowering physiology

\section{INTRODUÇÃO}

A videira (Vitis spp.) e outros membros da família Vitaceae caracterizam-se por apresentar inflorescências ou gavinhas em posição oposta às folhas e uma hierarquia de gemas de diferentes ordens nas axilas das folhas. O complexo de gemas axilares da videira inclui uma gema lateral, ou gema pronta, e uma gema composta, também denominada gema latente (Morrison, 1991).

Gemas latentes completamente maduras, contendo um ou mais primórdios de inflorescência, são chamadas gemas férteis ou frutíferas. Gemas inférteis ou vegetativas são gemas latentes que contêm primórdios de gavinha no lugar de primórdios de inflorescência (Srinivasan \& Mullins, 1981).

Qualquer desequilíbrio entre os fatores envolvidos na formação dos primórdios de inflorescência pode levar o primórdio não comprometido a diferenciar-se em gavinha ou brotação vegetativa. Algumas vezes, um primórdio de inflorescência parcialmente diferenciado pode reverter-se a primórdio de gavinha, fenômeno que é conhecido como 'filagem' (Shikhamany, 1999).

Segundo Srinivasan \& Mullins (1981), diversos fatores influenciam na fertilidade de gemas em videiras, tais como: característica varietal, vigor dos ramos, temperatura ambiente, intensidade luminosa, fotoperíodo, nutrição mineral, disponibilidade de água, níveis endógenos de fitormônios e aplicações de reguladores vegetais.

O excesso de vigor dos ramos é um dos fatores que pode levar à redução da fertilidade de gemas em videiras. Shikhamany (1999) verificou correlação negativa entre comprimento de entrenós e a produtividade da videira Sultanina.

Um dos problemas relacionados ao alto vigor em videiras é a ocorrência da necrose de gemas. Normalmente, esta necrose ocorre apenas na gema primária central, mantendo as gemas secundárias sadias. Posteriormente, estas se desenvolvem em brotações que, na maioria das vezes, apresentam baixa fertilidade, levando a uma baixa produtividade das videiras (Lavee et al., 1993).
Shikhamany (1999) sugere que a adoção de práticas culturais apropriadas para reduzir o vigor excessivo dos ramos e aumentar a incidência de luz nas gemas, pode incrementar a fertilidade de gemas. Dentre estas práticas culturais, podem-se citar: o uso de porta-enxertos menos vigorosos, o controle da adubação e da irrigação e o emprego de reguladores vegetais (Albuquerque, 1998).

Cloreto de clorocolina, ou cloreto de 2-cloro etil-trimetil amônio, também conhecido como chlomerquat, cycocel ou CCC, é um retardador de crescimento, cuja ação está relacionada à inibição da síntese de giberelina endógena. No Brasil, é amplamente utilizado em várias culturas, tais como o algodão e o trigo (Hertwig, 1983).

Em videiras da cultivar Sultanina, Reddy \& Shikhamany (1989) constataram aumento da fertilidade de gemas mediante aplicação de cycocel a $1000 \mathrm{mg} . \mathrm{L}^{-1}$, no estádio de $5^{\mathrm{a}}$ folha. Este tratamento aumentou a fertilidade média de gemas entre o $5^{\circ}$ e o $12^{\circ}$ nó, de $27,5 \%$ para $43,8 \%$.

Chekol (1994) estudou o efeito da aplicação de cycocel a 3\%, antes da brotação das gemas das cultivares de videira Flame Seedless e Superior Seedless, e observou que este tratamento atrasou o início da formação, mas aumentou o número e o tamanho dos primórdios de inflorescência.

Em videiras da cultivar Itália, Motoyke (1994) fez cinco pulverizações de cycocel nas doses de $0 ; 50 ; 100 ; 150$ e 200mg.L.-1, em intervalos quinzenais, a partir do estádio de $15^{\mathrm{a}}$ folha, e constatou aumento linear do número de cachos.

De acordo com Motoyke (1994), uma das principais causas das baixas produtividades verificadas em vinhedos, em algumas regiões do Estado de São Paulo, é a baixa fertilidade de gemas. Neste contexto, este trabalho objetivou estudar os efeitos de aplicações de cycocel na fertilidade de gemas e no crescimento dos ramos de videiras da cultivar Itália.

\section{MATERIALEMÉTODOS}

O experimento foi conduzido em vinhedo comercial da cv. Itália, localizado no Município de São Miguel Arcanjo, região sul do Estado de

\footnotetext{
(Trabalho 169/2003). Recebido: 07/11/2003. Aceito para publicação: 13/04/2004

${ }^{2}$ Eng. Agr. Dr. Prof. Adjunto, Departamento de Agronomia, UNICENTRO. Rua Simeão Varela de Sá, 03, CEP85040-080 Guarapuava-PR. E-mail: rbotelho@ unicentro.br. ${ }^{3}$ Bolsista Pós-doutorado FAPESP

${ }^{4}$ Eng. Agr. Dr. Pesquisador Científico. Instituto Agronômico (IAC). Caixa Postal 28, 13001-970 Campinas-SP. E-mail: ejppires@ cec.iac.br
} 

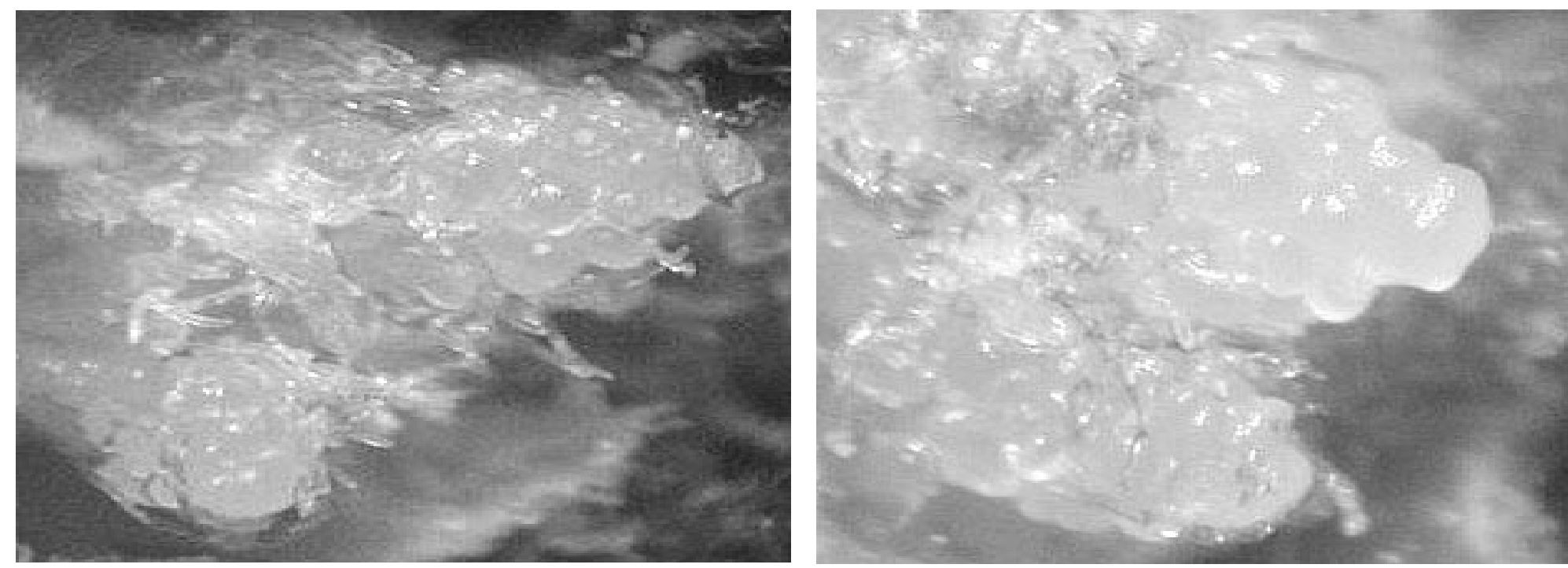

FIGURA 1 - Primórdios de inflorescência em gemas dormentes de videira da cultivar Itália.

São Paulo, com coordenadas geográficas de $23^{\circ} 52^{\prime} \mathrm{S}$ e $48^{\circ} 00^{\prime} \mathrm{W}$, altitude de $650 \mathrm{~m}$ e clima Cfa, segundo Köeppen. As videiras se encontravam no $18^{\mathrm{a}}$ ano de produção, enxertadas sobre o porta-enxerto 420-A, no espaçamento 4,5 × 2,5 m, e conduzidas no sistema de pérgula.

Os tratamentos consistiram das seguintes doses de cycocel: 0 ; $500 ; 1.000 ; 1.500 ; 2.000$ e $2.500 \mathrm{mg} . \mathrm{L}^{-1}$. As aplicações foram realizadas através de pulverização dos ramos, 60 dias após a poda, em 21 de setembro de 2001, quando os ramos apresentavam 10 folhas. Para o preparo das soluções, utilizou-se o produto comercial Tuval® (Microquímica) contendo 100 g.L. $\mathrm{L}^{-1}$ de cycocel.

O delineamento experimental foi em blocos casualizados, com 6 tratamentos e 4 repetições, e parcelas constituídas por uma planta. Cinco ramos de cada parcela experimental foram retirados por ocasião da dormência das videiras, em 30 de junho de 2002.

Para cada ramo, foram realizadas as seguintes avaliações:

1. Fertilidade de gemas: cada uma das 15 gemas basais do ramo foi cortada transversalmente na terça parte superior, dessecada e examinada sob estéreo microscópio com aumento de 45 vezes, verificando se havia presença ou não de primórdio de inflorescência e a ocorrência de gemas mortas. Morfologicamente, o primórdio de inflorescência completamente desenvolvido de uma gema dormente madura apresentava-se na forma de um eixo com inúmeras protuberâncias, correspondentes às futuras flores a serem formadas, assemelhando-se a um cacho de uva (Figura 1) (Srinivasan \& Mullins, 1981).

2. Distribuição das gemas férteis por setor: os ramos foram divididos em 3 setores, compreendendo os intervalos da $1^{\text {a }}$ à $5^{\text {a }}$ gema, da $6^{a}$ à $10^{a}$ gema e da $11^{\mathrm{a}}$ à $15^{\mathrm{a}}$ gema, contadas a partir da base dos ramos. Posteriormente, calculou-se a proporção das gemas férteis por setor, expressa em porcentagem.

3. Diâmetro de entrenós: $O$ diâmetro dos quinze primeiros entrenós de cada ramo foi medido com auxílio de um paquímetro digital, sendo os resultados expressos em milímetros. Posteriormente, calculouse a média do diâmetro dos entrenós de cada ramo.

4. Comprimento dos entrenós: O comprimento de cada ramo foi medido com auxílio de uma trena graduada, sendo os resultados expressos em centímetros. A partir dos resultados, calculou-se o comprimento médio de cada entrenó.

5. Peso fresco dos entrenós: A massa de cada ramo foi medida com auxílio de uma balança eletrônica, sendo os resultados expressos em gramas. Posteriormente, calculou-se o peso fresco médio de cada entrenó.

Os resultados foram submetidos à análise de variância e regressão polinomial.

\section{RESULTADOSE DISCUSSÃO}

Aplicações de cycocel aumentaram linearmente a porcentagem de gemas férteis em videiras da cultivar Itália (Figura 2). A fertilidade de gemas aumentou de 40,5\% na testemunha, para 58,95\% nos ramos tratados com cycocel a $2.500 \mathrm{mg} . \mathrm{L}^{-1}$. De acordo com Reddy \& Shikhamany (1989), o cycocel pode aumentar a fertilidade de gemas em videiras por reduzir o crescimento vegetativo, evitando o sombreamento das gemas, e por inibir a síntese de giberelina endógena, aumentando conseqüentemente a relação citocinina/giberelina endógena.

Segundo Mullins et al. (2000), giberelinas promovem a formação de primórdios indiferenciados, o primeiro passo da diferenciação floral, no entanto, na fase seguinte de diferenciação, giberelinas levam à formação de primórdios de gavinhas, enquanto as citocininas promovem a formação de primórdios de inflorescência.



FIGURA 2 - Porcentagem de gemas férteis em videiras cv. Itália tratadas com cycocel.

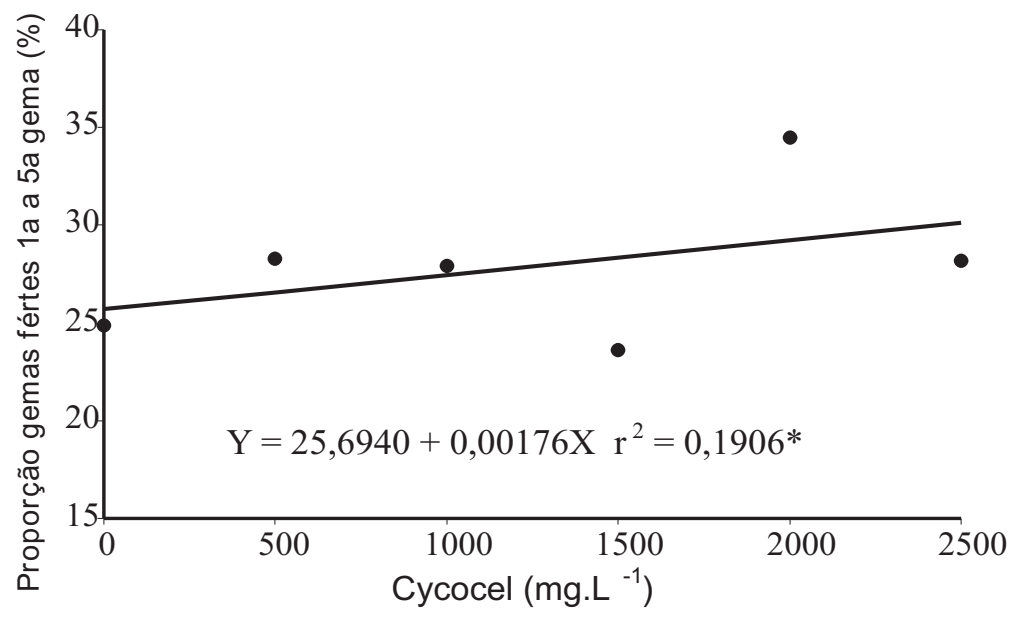

FIGURA 3 - Proporção de gemas férteis (\%) entre a $1^{\text {a }}$ e a $5^{\mathrm{a}}$ gema basal em videiras cv. Itália tratadas com cycocel 
Aplicações de cycocel também aumentaram linearmente a proporção de gemas férteis entre a $1^{\mathrm{a}}$ e a $5^{\mathrm{a}}$ gema basal (Figura 3 ). A proporção das gemas férteis neste setor do ramo aumentou de $22,4 \%$ na testemunha, para $31,6 \%$ em ramos tratados com cycocel a $2.500 \mathrm{mg}^{-\mathrm{L}^{-1}}$ (Figura 4). Segundo Mullins et al. (2000), a sequiência de diferenciação floral ocorre das gemas basais do ramo em direção ao ápice e, portanto, as gemas basais possivelmente foram as mais influenciadas pela aplicação do cycocel no início do ciclo vegetativo.

O cycocel também reduziu a porcentagem de gemas mortas, apresentando efeito quadrático para esta variável (Figura 5). A dose de cycocel estimada para a menor porcentagem de gemas mortas obtida pela maximização da função foi de $1.416,4 \mathrm{mg} \cdot \mathrm{L}^{-1}$. Lavee et al. (1993) relacionaram a ocorrência de necrose em gemas de videiras a níveis elevados de giberelina endógena. Ramos excessivamente vigorosos, que normalmente apresentaram alta incidência de necrose de gemas, tinham maior atividade de giberelina nas gemas, quando comparados a ramos de crescimento moderado. Desta forma, como o cycocel é um inibidor da síntese de giberelinas, aplicações exógenas deste retardador de crescimento poderiam reduzir os níveis endógenos de giberelinas, diminuindo a mortalidade de gemas.



FIGURA 4 - Distribuição das gemas férteis (\%) por setor do ramo em videiras cv. Itália.

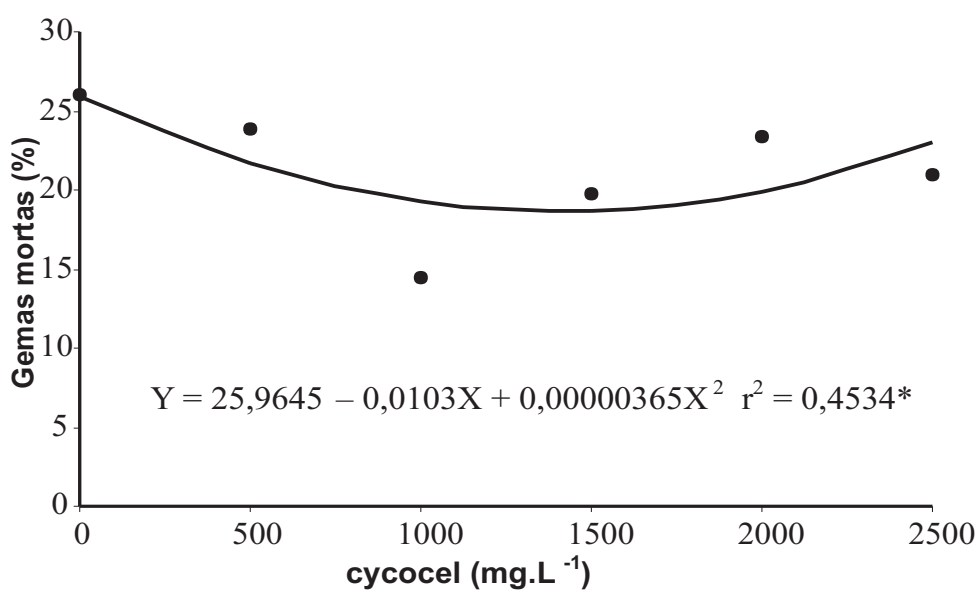

FIGURA 5 - Porcentagem de gemas mortas em videiras cv. Itália tratadas com cycocel.

Adicionalmente, aplicações de cycocel reduziram o peso fresco dos entrenós, apresentando efeito quadrático para esta variável (Figura 6). Este resultado era esperado, tendo em vista que este produto é um retardador de crescimento, muito utilizado em culturas anuais para inibir o desenvolvimento vegetativo. Possivelmente, este efeito poderia ser um dos responsáveis pelo aumento da fertilidade de gemas em videiras da cultivar Itália. Shikhamany (1999) relaciona o excesso de vigor como uma das principais causas da baixa fertilidade em videiras, devido principalmente ao sombreamento das gemas.

Não houve diferenças significativas para as variáveis diâmetro e comprimento dos entrenós, no entanto observou-se tendência de redução do diâmetro dos entrenós nas plantas tratadas com cycocel (Tabela 1).



FIGURA 6 - Peso fresco de entrenós (g) de videiras cv. Itália tratadas com cycocel.

TABELA 1 - Comprimento (cm) e diâmetro ( $\mathrm{mm}$ ) de internódios de videiras cv. Itália tratadas com cycocel.

\begin{tabular}{ccc}
\hline $\begin{array}{c}\text { Doses cycocel } \\
\left(\mathrm{mg.L}^{-1}\right)\end{array}$ & $\begin{array}{c}\text { Comprimento } \\
\text { entrenós }(\mathrm{cm})\end{array}$ & $\begin{array}{c}\text { Diâmetro } \\
\text { Entrenós }(\mathrm{mm})\end{array}$ \\
\hline 0 & 8,35 & 8,11 \\
500 & 7,94 & 7,63 \\
1000 & 7,96 & 7,74 \\
1500 & 8,24 & 7,89 \\
2000 & 8,40 & 7,71 \\
2500 & 8,53 & 7,95 \\
\hline CV $(\%)$ & 8,21 & 5,84 \\
$F$ & 0,4117 & 0,7824 \\
\hline
\end{tabular}

Pelos resultados apresentados, ficou evidente a possibilidade de utilização do cycocel para o aumento da fertilidade de gemas em videiras cv. Itália que se encontram em desequilíbrio, com excessivo vigor e, portanto, com baixa diferenciação floral. Novos estudos deverão ser conduzidos visando a avaliar os seus efeitos na produtividade das plantas, qualidade dos frutos e impacto ambiental.

\section{CONCLUSÕES}

1-) Aplicações de cycocel, 60 dias após a poda, aumentaram a porcentagem de gemas férteis e a proporção de gemas férteis entre a $1^{\text {a }}$ e a $5^{\text {a }}$ gema basal dos ramos em videiras cv. Itália .

2-) Aplicações de cycocel reduziram a massa fresca dos internódios e a porcentagem de gemas mortas em videiras cv. Itália.

\section{REFERÊNCIAS BIBLIOGRÁFICAS}

ALBUQUERQUE, T.C.S. Absorção de macronutrientes pelas cultivares de videira Thompson Seedless e Itália sob efeito de diferentes retardadores de crescimento e porta-enxertos. 1998. 69f. Tese (Doutorado) - Escola Superior de Agricultura "Luiz de Queiroz", Universidade de São Paulo, Piracicaba, 1998.

CHEKOL, T. Effects of some growth regulators on the initiation and differentiation of embryonic inflorescences in some grapevine cultivars. Bulletin de l'OIV, Paris, v.67, n.759-760, 1994. 
HERTWIG, K.V. Manual de herbicidas, desfolhantes, dessecantes, fitorreguladores e bioestimulantes. São Paulo: Ceres, 1983. 669p.

LAVEE, S.;ZIV, M.; MELAMUD, H.; BERNSTEIN, Z. The involvement of gibberelins in controlling bud development of grapevines (Vitis vinifera L.). Acta Horticulturae, Leiden, v.329, p.177-182, 1993.

MORRISON, J.C. Bud development in Vitis vinifera L.. Bottanical Gazette, Chicago, v.153, n.3, p.304-315, 1991.

MOTOYKE, S.Y. Retardantes de crescimento na produção de videira (Vitis vinifera L.) cv. Itália na região oeste do Estado de São Paulo. 1994. 70f. Dissertação (Mestrado) - Universidade Federal de Viçosa, Viçosa, 1994.

MULLINS, M.G.; BOUQUET, A.; WILLIAMS, L.E. Biology of the grapevine. Cambridge: University Press, 2000. 239p.
REDDY, N.N.; SHIKHAMANY, S.D. Effects of CCC and MH sprays on bud fruitfullness in Thompson Seedless grape. Journal of Maharashtra Agricultural Universities, Pune, v.14, n.3, p.316-318, 1989.

SHIKHAMANY, S.D. Physiology and cultural practices to produce seedless grapes in tropical environments. In: CONGRESSO BRASILEIRO DE VITICULTURA E ENOLOGIA, 9., 1999, Bento Gonçalves. Anais... Bento Gonçalves: Embrapa-CNPUV, 1999, p.4348

SRINIVASAN, C.; MULLINS, M.G. Physiology of flowering in the grapevine - A review. American Journal of Enology and Viticulture, Davis, v.32, n.1, p.47-63, 1981. 